\title{
Targeting the MET receptor tyrosine kinase in non-small cell lung cancer: emerging role of tivantinib
}

This article was published in the following Dove Press journal:

Cancer Management and Research

4 October 2014

Number of times this article has been viewed

\author{
Eberechi S Agwa \\ Patrick C Ma \\ Translational Hematology and \\ Oncology Research, Taussig Cancer \\ Institute, Cleveland Clinic, Cleveland, \\ $\mathrm{OH}$, USA
}

\begin{abstract}
MET receptor tyrosine kinase and its natural ligand, hepatocyte growth factor, have been implicated in a variety of cancers, including non-small cell lung cancer (NSCLC). Mechanisms by which cellular deregulation of MET occurs include overexpression, genomic amplification, mutation, or alternative splicing. MET overexpression or activation is a known cause of acquired resistance to epidermal growth factor receptor (EGFR) tyrosine kinase inhibitors in NSCLC. Inhibition of MET signaling in these EGFR tyrosine kinase inhibitor-resistant cells may potentially restore sensitivity to EGFR inhibitors. Tivantinib (ARQ 197), reported as a small-molecule MET inhibitor, has demonstrated antitumor activity in early clinical studies. This review focuses on MET and lung cancer, the clinical development of tivantinib, the clinical trials of tivantinib in NSCLC to date, its current/emerging role in the management of NSCLC, and future directions.
\end{abstract}

Keywords: MET inhibitor, tivantinib, ARQ 197, non-small cell lung cancer

\section{Introduction}

MET is a cell surface receptor tyrosine kinase with specific natural ligand hepatocyte growth factor (HGF), also called scatter factor. The MET/HGF signaling cascade is involved in regulating a wide array of cellular functions, including cell proliferation, survival and apoptosis, motility and migration, invasion, branching morphogenesis, angiogenesis, and metastasis. ${ }^{1-4}$

MET signaling activity is normally found in specific stages of development in utero, ${ }^{5-9}$ plays a role in wound repair, ${ }^{10-13}$ and is activated in degenerative diseases like lung fibrosis and liver cirrhosis. ${ }^{14-16}$

While MET is typically in a quiescence signaling state in adult tissues physiologically, aberrant MET expression with associated signaling deregulation is widely observed in solid malignancies, including colon, gastric, breast, ovarian, pancreatic, and lung tumors as well as hematological malignancies. ${ }^{1,17-19}$ Mechanisms by which cellular deregulation of MET can occur include MET receptor overexpression, genomic amplification, mutation, or alternative splicing, ${ }^{2,3,20}$ leading to oncogenic signaling with resultant tumor angiogenesis, cell proliferation, survival, migration, resistance to apoptosis, aggressive cellular invasion, and metastasis. ${ }^{1,17,19}$

MET overexpression and mutation correlate with a poor clinical prognosis in human cancer. ${ }^{1,21,22}$ Recent evidence has demonstrated the presence of signaling cross-talk with the epidermal growth factor receptor (EGFR) and Kirsten rat sarcoma viral oncogene homolog (KRAS) signaling pathways critical in the development of intrinsic or acquired resistance to EGFR inhibitors in non-small cell lung cancer (NSCLC). ${ }^{23}$ Inhibition
Translational Hematology and Oncology Research, Taussig Cancer Institute,

Cleveland Clinic, Cleveland,

$\mathrm{OH} 44195$, USA

Tel + I 2 I 64455545

$\mathrm{Fax}+\mathrm{I} 2166362498$

Email map@ccf.org 
of MET signaling in these EGFR tyrosine kinase inhibitor (TKI)-resistant cells may potentially restore sensitivity to EGFR inhibitors in these resistant cells. Furthermore, dual blockade of MET and EGFR may impair growth in these tumor cells. 2,20,24 Thus, small-molecule inhibitors of MET and monoclonal antibodies against MET and HGF have become the subject of a number of cancer clinical trials in recent years. ${ }^{25}$

\section{MET-targeting inhibitory agents}

Several MET-targeting inhibitory agents have shown promising results in clinical trials recently. A monovalent monoclonal antibody against MET (onartuzumab; Table 1) has shown activity in combination with erlotinib in NSCLC patients. ${ }^{26}$ Further, there was improvement in overall survival in patients with gastric adenocarcinoma treated with the HGF monoclonal antibody AMG 102 (rilotumumab). ${ }^{27}$ The best response profile was observed in patients with high MET expression levels in both of these studies. Ficlatuzumab, another humanized anti-HGF monoclonal antibody, is currently in Phase Ib/II studies in combination with erlotinib in Asian patients with locally advanced or metastatic lung cancer who were never smokers or ex-light smokers (NCT 01039948). XL184 (cabozantinib) a multitarget MET inhibitor that also inhibits vascular endothelial growth factor (VEGF) receptor 2 and "rearranged during transfection" protooncogene (RET), has been shown to be effective against multiple solid tumors, such as medullary thyroid cancer, breast cancer, NSCLC, melanoma, prostate cancer, and liver cancer. ${ }^{28}$ Crizotinib, a small-molecule inhibitor of MET and anaplastic lymphoma kinase (ALK), is approved for treatment in patients with $A L K$ translocation-positive NSCLC as determined by $A L K(2 \mathrm{p} 23)$ break-apart fluorescent in situ hybridization. There has been a case report describing a patient with de novo $M E T$ amplification and no $A L K$ rearrangement who achieved a rapid response to crizotinib. ${ }^{29}$ In patients with KRAS mutations and who are EGFR inhibitor naïve, the combination of Tivantinib (ARQ 197), a selective non-adenosine triphosphate (ATP) competitive inhibitor of MET, and erlotinib demonstrated an improvement in progression-free survival (PFS) (hazards ratio [HR] 0.18 ; $95 \%$ confidence interval $[\mathrm{CI}] 0.05-0.70 ; P<0.01)$ and overall survival OS (HR $0.43 ; 95 \%$ CI $0.12-1.50 ; P=0.17$ ). Other Phase I/II trials of tivantinib have demonstrated promising activity in hepatocellular, pancreatic (in combination with gemcitabine), and colorectal (in combination with cetuximab and irinotecan) cancers. ${ }^{30,31}$ This review focuses on MET and lung cancer, the clinical development of tivantinib, clinical trials with tivantinib in NSCLC to date, its current/emerging role in the management of NSCLC, and future directions.

\section{MET and lung cancer}

MET was originally isolated from a chemical carcinogeninduced human osteosarcoma-derived cell line and is expressed primarily by epithelial cells. ${ }^{20}$ It is a transmembrane receptor tyrosine kinase with an extracellular alpha chain and a transmembrane beta chain linked by disulfide bonds. ${ }^{20}$ Compared with other human cancers, MET and HGF are most commonly expressed in lung tumors $(72 \%)^{32}$ and MET's critical role in the pathophysiology of NSCLC has been demonstrated in animal models and human NSCLC cell lines. ${ }^{32,33}$ Forty-one NSCLC cell lines and more than 150 NSCLC tumor samples were analyzed by Rikova et al in a phosphoproteomics survey study to characterize tyrosine kinase signaling, and MET receptor was ranked as the most highly phosphorylated receptor tyrosine kinase in NSCLC tumor samples. ${ }^{33}$ Ma et al analyzed paraffin-embedded, formalinfixed tissues from 32 patients with lung cancer using standard immunohistochemical techniques. There was expression of MET in all $(100 \%)$ lung cancer tissues examined $(n=32) .{ }^{34}$ Phosphorylation of focal adhesion proteins, such as paxillin, p125FAK, and PYK2, has also been demonstrated to occur in response to MET activation in lung cancer cells. ${ }^{36}$ Activating mutations in the MET gene have been identified and lead to MET autophosphorylation and downstream phosphorylation of 3-phosphoinositide-dependent protein kinase 1, AKT, mammalian target of rapamycin, and S6K. Primary MET amplification is uncommon, occurring in 4\%-21\% of patients with NSCLC and up to $4 \%$ of patients with adenocarcinoma, and is associated with a poor prognosis. ${ }^{36-40} \mathrm{Up}$ to $57 \%$ of patients with squamous histology and $27 \%-77 \%$ with nonsquamous histology have been found to have overexpression of MET protein..$^{20,26,34,41-44}$ However, the definition of MET overexpression varied in these studies. One of the studies is a randomized multicenter Phase II study in patients with locally advanced and metastatic NSCLC in which MET-high was defined as $\geq 50 \%$ of tumor cells with moderate $(2+)$ or strong (3+) staining intensity by immunohistochemistry. ${ }^{26}$

\section{Selective inhibition of MET with MET TKI}

As proof-of-principle, the prototype preclinical MET TKI SU11274 and small interfering RNA have been shown in previous studies to inhibit growth and viability of METexpressing tumor cells as well as nullification of METmediated downstream signaling. ${ }^{34,45}$ In vivo growth of 
NSCLC xenografts was significantly inhibited in animals treated with a bivalent humanized anti-MET antibody (h224G11) with near complete resolution observed in animals treated with both h224G11 and vinorelbine, reported by Goetsch et al. ${ }^{46}$ PHA665752, a preclinical MET-specific TKI, has been shown to inhibit MET phosphorylation, impede angiogenesis by $>85 \%$, reduce tumorigenicity by $>75 \%$, and induce regression of established tumors in mouse xenografts. ${ }^{47}$ Tivantinib, an oral, selective, small-molecule inhibitor of MET, impedes constitutive and HGF-induced MET phosphorylation by stabilizing the inactive conformation and reducing downstream signaling, ${ }^{48,49}$ leading to a reduction in invasion, metastasis, and proliferation, and induction of caspase-dependent apoptosis.

\section{Clinical development of tivantinib}

Among the agents in the new class of trans-3, 4-bisubstituted pyrrolidine-2, 5-diones, tivantinib is the most advanced in therapeutic development. ${ }^{49}$ It binds MET in its inactive or nonphosphorylated form and maintains this inactive state. Tivantinib demonstrates high in vitro potency with an inhibitory constant $\left[\mathrm{K}_{\mathrm{i}}\right]$ of $\sim 35.5 \mathrm{nM}$ on kinetic analyses and also a high degree of kinase selectivity compared with other MET inhibitors. ${ }^{49-51}$ It inhibits both constitutive and ligandmediated MET autophosphorylation in different cancer cell lines, with a peak effect seen by 24 hours and lasting for about 8-12 hours following withdrawal of tivantinib. ${ }^{52}$ Significant tumor growth reductions ranging from $45 \%$ to $79 \%$ have been shown in xenograft mouse models using several human cancer cell lines (colon, gastric, breast, prostate, pancreatic) at an orally administered tivantinib dose of $200 \mathrm{mg} / \mathrm{kg}$. ${ }^{49,53,54}$ Tivantinib also showed the capacity to prevent bone metastases in a humanized mouse model of metastatic breast cancer as well as inhibition of liver metastases in murine xenograft models. ${ }^{53,54}$

In 2006, an initial Phase I dose-escalation study of monotherapy with tivantinib was completed in 74 patients with metastatic solid tumors. ${ }^{55-57}$ The drug was well tolerated on both an intermittent and a continuous dosing schedule, with no dose-limiting toxicities observed. ${ }^{55-57}$ The most common side effects were fatigue (16.2\%), nausea (13.5\%), vomiting $(6.8 \%)$, and diarrhea (5.6\%). Of the 74 patients enrolled, 61 were evaluable by Response Evaluation Criteria in Solid Tumors (RECIST) 1.0 criteria. $^{56}$ Three $(5 \%)$ of these 61 patients achieved a partial response, $38(62 \%)$ had stable disease, and $20(33 \%)$ experienced disease progression. Overall disease control (complete response + partial response + stable disease) was demonstrated in 41 patients $(67 \%) .{ }^{56} \mathrm{~A}$ follow-up Phase I trial established $300 \mathrm{mg}$ twice daily as the maximum tolerated dose, but this was subsequently adjusted to $360 \mathrm{mg}$ twice daily following introduction of a modified commercial formulation. ${ }^{58}$ The safety of this adjusted dose was verified in an expanded cohort of 20 patients. ${ }^{59,60}$ Tivantinib has shown antitumor activity in a Phase II monotherapy study in patients with microphthalmia transcription factor-associated tumors. ${ }^{61}$ The results of Phase II studies in patients with unresectable hepatocellular cancer (NCT 00802555) and in patients with relapsed/refractory germ cell tumors (NCT 01055067) are awaited. Another Phase I dose-escalation study in combination with sorafenib in advanced solid tumors (NCT00827177) suggests that combined inhibition of MET and angiogenic signaling may have therapeutic potential. ${ }^{62}$ Its favorable safety profile has also been reported when used in combination with gemcitabine for advanced solid tumors (NCT 00874042) ${ }^{63}$ as well as with irinotecan and cetuximab in metastatic colorectal cancer (NCT 01075048). ${ }^{64}$

\section{Clinical trials in NSCLC Phase I dose-escalation study of tivantinib + erlotinib}

This trial assessed the safety, pharmacokinetics, and preliminary antitumor activity of tivantinib combined with erlotinib, an EGFR inhibitor. Thirty-two patients with advanced solid tumor malignancies received combination treatment with escalating doses of tivantinib. The most common tumor type was NSCLC, occurring in eight (25\%) of the 32 patients. ${ }^{65}$ Continuous therapy with the combination of erlotinib and tivantinib was well tolerated. Five patients $(15.6 \%)$ had treatment-related serious adverse events including neutropenia, leukopenia, syncope, sinus bradycardia, and sick sinus syndrome. Fifteen $(46.8 \%)$ of the 32 patients had a partial response $(n=1)$ or stable disease $(n=14)$. Of the eight patients with NSCLC, six had stable disease. Five of these six NSCLC responders had been treated previously with erlotinib monotherapy. The recommended dose for tivantinib was $360 \mathrm{mg}$ twice daily in combination with erlotinib $150 \mathrm{mg}$ daily. ${ }^{65}$ This combination therapy was therefore deemed to be safe. Further, it illustrates that inhibition of multiple pathways through combination therapy is a plausible strategy to overcome drug resistance.

\section{Erlotinib + tivantinib versus erlotinib + placebo in previously treated advanced NSCLC}

Patients $(\mathrm{n}=167)$ in this randomized Phase II study had inoperable locally advanced or metastatic NSCLC and 
had received at least one line of chemotherapy but were EGFR inhibitor-naïve. ${ }^{66}$ Eligible patients were randomly assigned to receive erlotinib $150 \mathrm{mg}$ daily + tivantinib $360 \mathrm{mg}$ twice daily (ET group, $\mathrm{n}=84$ ) or erlotinib $150 \mathrm{mg}$ daily + placebo (EP group, $n=83$ ), both on 28-day cycles. The primary endpoint was median PFS, which was 3.8 months and 2.3 months for the ET group and EP group, respectively (HR 0.81 , CI $0.57-1.16 ; P=0.24)$. Analyses of specific subgroups demonstrated a trend toward clinical benefit in the treatment arm (ET) in patients with EGFR wild-type status, increasing $M E T$ fluorescent in situ hybridization number, nonsquamous histology, and KRAS mutation. The HR for PFS in the limited cohort of $K R A S$ mutant patients was 0.18 (95\% CI 0.05-0.70, $P=0.006)$. In the intention-to-treat population treated with ET, time to new metastatic lesions was significantly higher at 7.3 months versus 3.6 months in the EP group $(P<0.01)$. Overall, there were no significant differences in adverse events between the treatment and control arms. The primary endpoint (PFS) was not met, but interesting findings were seen, especially in the $K R A S$ mutant cohort. The sample size was small compared with the number of subgroup analyses performed. ${ }^{66}$ There was also a trend toward benefit in both PFS (HR 0.71; 95\% CI 0.46-1.10; $P=0.12$ ) and overall survival (HR $0.72 ; 95 \%$ CI $0.44-1.17 ; P=0.18$ ) among patients with nonsquamous histology $(n=117)$ in the ET arm. An adjusted PFS HR of 0.61 (95\% CI $0.39-0.98 ; P=0.04)$ and an adjusted overall survival HR of 0.58 (95\% CI $0.34-0.99$; $P=0.04$ ) for patients with nonsquamous histology was shown following application of the proportional hazards model for the intention-to-treat population. ${ }^{66}$

\section{MARQUEE trial in patients with advanced NSCLC}

Based on the results of the Phase II study, the randomized Phase III MARQUEE trial (NCT01244191) was initiated. PFS and overall survival were significantly improved in patients with nonsquamous histology in the treatment arm (ET) compared with the control arm (EP) in the Phase II study. The rationale for this trial was to enrich the study population with MET-high tumors by limiting enrollment to nonsquamous NSCLC. The primary endpoint was overall survival. Secondary and exploratory endpoints included PFS, overall survival in biological subgroups (defined by EGFR and $K R A S$ mutation status, MET amplification or overexpression, serum hepatocyte growth factor), and safety. ${ }^{67}$

Approximately 1,000 patients were recruited from more than 200 clinical study sites worldwide by May 2012 . A preplanned interim analysis in October 2012 showed that the study would not meet its primary endpoint of improved overall survival, leading to the sponsor's decision to discontinue the study via the independent data monitoring committee. ${ }^{68}$ Of note, however, there were no safety issues identified by the independent data monitoring committee. Despite improvement in PFS in the intention-to-treat population, this benefit did not influence overall survival.

A further exploratory analysis was performed in 445 patients evaluable by MET immunohistochemistry. Of these, 211 patients were MET-high as characterized in the study protocol. Substantial improvement in overall survival was seen in the MET-high treatment arm compared with the control arm, a benefit not seen in the intention-to-treat population. ${ }^{69}$ On the other hand, there was no difference in overall survival seen in 234 patients confirmed to be MET-low. ${ }^{69}$ PFS was similar in the MET-high and MET-low groups. Efficacy data on subsets of patients according to MET protein expression in tumor samples were presented at the European Cancer Congress meeting in 2013. Both PFS and overall survival were longer in patients treated with combined MET-EGFR inhibition when tumors showed at least $2+$ positive MET immunostaining in more than $50 \%$ of tumor cells. ${ }^{70}$

\section{ATTENTION trial: tivantinib + erlotinib versus placebo + erlotinib}

The primary endpoint in ATTENTION, a randomized, doubleblind, placebo-controlled, Phase III study (NCT01377376), was overall survival in subjects who had locally advanced or metastatic nonsquamous NSCLC with wild-type EGFR, treated with tivantinib + erlotinib or erlotinib monotherapy. The subjects could have received one to two prior systemic chemotherapies. ${ }^{71}$ In August 2012, the sponsor (Kyowa Hakko Kirin Co, Ltd, Tokyo, Japan) announced the temporary suspension of patient enrollment according to the recommendations of the safety review committee due to a higher frequency of interstitial lung disease as one of the drug-related adverse events in the study. ${ }^{72}$ The safety review committee met again after further investigation, leading to discontinuation of this trial in October 2012. ${ }^{73}$

\section{Erlotinib + tivantinib versus single-agent chemotherapy in previously treated KRAS mutation-positive subjects}

This randomized, open-label Phase II study (NCT01395758) was designed to investigate tivantinib + erlotinib versus singleagent chemotherapy in subjects with $K R A S$ mutation-positive NSCLC, with the primary endpoint of PFS. Chemotherapy 
is per physician's choice from pemetrexed, docetaxel, or gemcitabine. Secondary endpoints include overall survival, objective response rate, and safety. This study was active as at the time of this review but is currently not recruiting. ${ }^{74}$

\section{Tivantinib + erlotinib in patients with locally advanced or metastatic EGFR mutation-positive NSCLC}

The primary objective of this multicenter, open-label, singlearm Phase II study (NCT01580735) is to examine if the combination of tivantinib and erlotinib is active in subjects who have locally advanced or metastatic NSCLC with activating $E G F R$ mutation who experienced disease progression on EGFR TKI monotherapy. ${ }^{75}$ This study is ongoing, but is currently not recruiting.

\section{Current/emerging role of tivantinib in NSCLC and future directions}

Our understanding of the biology of MET and the clinical role of tivantinib inhibition in the MET signaling pathway for NSCLC are evolving. Tivantinib is currently not approved for use by the US Food and Drug Administration (FDA) and has not been licensed in any other country. The final results from the currently ongoing randomized Phase II study (NCT01395758) in KRAS-mutant NSCLC patients are eagerly awaited to verify if there is clinical benefit from the use of tivantinib and erlotinib in this unique patient

Table I Selective inhibitors of MET or HGF

\begin{tabular}{ll}
\hline Compound & Type of agent \\
\hline Targeting MET receptor & \\
AMG 208 & TKI \\
BMS 777607 & TKI \\
Compound I (Amgen) & TKI \\
EMD I2I $4063 /$ EMD I20483I & Bivalent mAb \\
H224GII & TKI \\
INC280 & TKI \\
JNJ38877605 & TKI \\
Onartuzumab (MET-mAb) & One arm mAb \\
MK-246I & TKI \\
MK 8033 & TKI \\
NK4 & HGF antagonist \\
PF42I7903 & TKI \\
SGXI26 & TKI \\
Tivantinib (ARQ I97) & TKI \\
Targeting HGF & \\
Ficlatuzumab & mAb \\
Rilotumumab & mAb \\
TAK-70I & mAb \\
\hline
\end{tabular}

Note: Amgen Inc. (Thousand Oaks, CA, USA).

Abbreviations: $\mathrm{mAb}$, monoclonal antibody; HGF, hepatocyte growth factor; TKI tyrosine kinase inhibitor. subgroup. The safety concerns (higher rates of interstitial lung disease) raised in the ATTENTION trial, although not reported in the other trials, warrant close vigilance and follow-up.

The results of the exploratory analysis from the MARQUEE trial suggest that there may be an overall survival benefit for patients with locally advanced or metastatic nonsquamous MET-high lung cancer who have received prior chemotherapy when they are treated with tivantinib in combination with erlotinib. However, the Phase III clinical trial study did not meet its preplanned primary objective of overall survival improvement in the intention-to-treat nonsquamous NSCLC patient population when tivantinib was used in combination with erlotinib. The results of the biomarker analysis will further clarify the predictive role of the MET receptor pathway to targeted therapy. At this time, the optimal strategies to appropriately select patients for optimal use of MET-targeting inhibition using tivantinib remain to be better defined, ie, whether tivantinib should be used as single agent or in combination with an EGFR TKI. A recent study by Katayama et al raised the possibility of an alternative underlying mechanism of action for tivantinib rather than specific inhibition of the MET receptor. To assess whether the antitumor activity of tivantinib is due to inhibition of MET, Katayama et $\mathrm{al}^{76}$ compared the activity of tivantinib with that of other MET inhibitors in both $M E T$-addicted and $M E T$-nonaddicted cancer cells. The MET inhibitors crizotinib and PHA 665752 suppressed the growth of MET-addicted cancers, but not the growth of cancers that are not addicted to $M E T$. On the other hand, tivantinib equally inhibited the growth of both $M E T$-addicted and MET-nonaddicted cells, suggesting that tivantinib works in a manner independent of $M E T$ status. Similar to vincristine, tivantinib induced G2-M cell cycle arrest in EBC1 cells, whereas other MET inhibitors induced G0-G1 cell cycle arrest. Further analysis demonstrated the microtubule as a target for tivantinib, causing typical microtubule disruption. Hence, it was suggested that in addition to inhibiting MET, tivantinib also inhibits microtubule polymerization.

The challenge remains in fine-tuning the most objective and reproducible way of identifying the patient subgroups that would most likely respond to MET-targeted inhibition, such as with the use of tivantinib. The potential of MET-high tumors to represent such a patient cohort remains an interesting premise, with some promising clinical data having emerged recently. However, this has certainly not come to full clinical fruition yet. There are difficulties in establishing a reliable and reproducible predictive biomarker assay for MET targeted therapy, as 
in the case of immunohistochemistry versus fluorescent in situ hybridization versus quantitative polymerase chain reaction. This issue remains an active area of urgent unmet need and requires further studies and validation in the clinical arena. Newer biomarker assay technologies may render further help in overcoming these challenges, especially those that afford quantitative protein marker analysis in standard archival specimens, eg, quantitative tumor tissue proteomics and automated quantitative immunofluorescence assay technology.

\section{Disclosure}

PCM has received speaking and consulting honoraria from Daiichi-Sankyo Inc. The authors have no other conflicts of interest in this work.

\section{References}

1. Birchmeier C, Birchmeier W, Gherardi E, Vande Woude GF. Met, metastasis, motility and more. Nat Rev Mol Cell Biol. 2003;4(12): 915-925.

2. Comoglio PM, Giordano S, Trusolino L. Drug development of MET inhibitors: targeting oncogene addiction and expedience. Nat Rev Drug Discov. 2008;7(6):504-516.

3. Gherardi E, Birchmeier W, Birchmeier C, Vande Woude G. Targeting MET in cancer: rationale and progress. Nat Rev Cancer. 2012;12(2): 89-103.

4. Trusolino L, Bertotti A, Comoglio PM. MET signalling: principles and functions in development, organ regeneration and cancer. Nat Rev Mol Cell Biol. 2010;11(12):834-848.

5. Andermarcher E, Surani MA, Gherardi E. Co-expression of the HGF/SF and c-Met genes during early mouse embryogenesis precedes reciprocal expression in adjacent tissues during organogenesis. Dev Genet. 1996;18(3):254-266.

6. Bladt F, Riethmacher D, Isenmann S, Aguzzi A, Birchmeier C. Essential role for the c-Met receptor in the migration of myogenic precursor cells into the limb bud. Nature. 1995;376(6543):768-771.

7. Bussolino F, Di Renzo MF, Ziche M, et al. Hepatocyte growth factor is a potent angiogenic factor which stimulates endothelial cell motility and growth. J Cell Biol. 1992;119(3):629-641.

8. Streit A, Stern CD, Thery C, et al. A role for $\mathrm{HGF} / \mathrm{SF}$ in neural induction and its expression in Hensen's node during gastrulation. Development. 1995;121(3):813-824.

9. Takayama H, La Rochelle WJ, Anver M, Bockman DE, Merlino G. Scatter factor/hepatocyte growth factor as a regulator of skeletal muscle and neural crest development. Proc Natl Acad Sci U SA. 1996;93(12): $5866-5871$

10. Matsumoto K, Nakamura T. Hepatocyte growth factor: renotropic role and potential therapeutics for renal diseases. Kidney Int. 2001;59(6): 2023-2038.

11. Michalopoulos GK, DeFrances MC. Liver regeneration. Science. 1997;276(5309):60-66.

12. Nakamura T, Mizuno S, Matsumoto K, Sawa Y, Matsuda H. Myocardial protection from ischemia/reperfusion injury by endogenous and exogenous HGF. J Clin Invest. 2000;106(12):1511-1519.

13. Schmidt C, Bladt F, Goedecke S, et al. Scatter factor/hepatocyte growth factor is essential for liver development. Nature. 1995;373(6516): 699-702.

14. Liu Y, Yang J. Hepatocyte growth factor: new arsenal in the fights against renal fibrosis? Kidney Int. 2006;70(2):238-240.

15. Ueki T, Kaneda Y, Tsutsui H, et al. Hepatocyte growth factor gene therapy of liver cirrhosis in rats. Nat Med. 1999;5(2):226-230.
16. Watanabe M, Ebina M, Orson FM, et al. Hepatocyte growth factor gene transfer to alveolar septa for effective suppression of lung fibrosis. Mol Ther. 2005;12(1):58-67.

17. Furge KA, Zhang YW, Vande Woude GF. Met receptor tyrosine kinase: enhanced signaling through adapter proteins. Oncogene. 2000;19(49):5582-5589.

18. Zhang YW, Vande Woude GF. HGF/SF-met signaling in the control of branching morphogenesis and invasion. J Cell Biochem. 2003;88(2): 408-417.

19. Birchmeier C, Gherardi E. Developmental roles of HGF/SF and its receptor, the c-Met tyrosine kinase. Trends Cell Biol. 1998;8(10):404-410.

20. Cipriani NA, Abidoye OO, Vokes E, Salgia R. MET as a target for treatment of chest tumors. Lung Cancer. 2009;63(2):169-179.

21. Jiang W, Hiscox S, Matsumoto K, Nakamura T. Hepatocyte growth factor/scatter factor, its molecular, cellular and clinical implications in cancer. Crit Rev Oncol Hematol. 1999;29(3):209-248.

22. Jiang WG, Hiscox SE, Parr C, et al. Antagonistic effect of NK4, a novel hepatocyte growth factor variant, on in vitro angiogenesis of human vascular endothelial cells. Clin Cancer Res. 1999;5(11):3695-3703.

23. Feng Y, Thiagarajan PS, Ma PC. MET signaling: novel targeted inhibition and its clinical development in lung cancer. $J$ Thorac Oncol. 2012;7(2):459-467.

24. Bean J, Brennan C, Shih JY, et al. MET amplification occurs with or without T790M mutations in EGFR mutant lung tumors with acquired resistance to gefitinib or erlotinib. Proc Natl Acad Sci U SA. 2007;104(52):20932-20937.

25. Katayama R, Aoyama A, Yamori T, et al. Cytotoxic activity of tivantinib (ARQ 197) is not due solely to c-MET inhibition. Cancer Res. 2013;73(10):3087-3096.

26. Spigel DR, Burris HA 3rd, Greco FA, et al. Randomized, double-blind, placebo-controlled, phase II trial of sorafenib and erlotinib or erlotinib alone in previously treated advanced non-small-cell lung cancer. $J$ Clin Oncol. 2011;29(18):2582-2589.

27. Zhu M, Doshi S, Gisleskog PO, et al. Population pharmacokinetics of rilotumumab, a fully human monoclonal antibody against hepatocyte growth factor, in cancer patients. J Pharm Sci. 2014;103(1):328-336.

28. Smith DC, Smith MR, Sweeney C, et al. Cabozantinib in patients with advanced prostate cancer: results of a phase II randomized discontinuation trial. J Clin Oncol. 2013;31(4):412-419.

29. Ou SH, Kwak EL, Siwak-Tapp C, et al. Activity of crizotinib (PF02341066), a dual mesenchymal-epithelial transition (MET) and anaplastic lymphoma kinase (ALK) inhibitor, in a non-small cell lung cancer patient with de novo MET amplification. J Thorac Oncol. 2011;6(5):942-946.

30. Santoro A, Rimassa L, Borbath I, et al. Tivantinib for second-line treatment of advanced hepatocellular carcinoma: a randomised, placebocontrolled phase 2 study. Lancet Oncol. 2013;14(1):55-63.

31. Adjei AA, Schwartz B, Garmey E. Early clinical development of ARQ 197, a selective, non-ATP-competitive inhibitor targeting MET tyrosine kinase for the treatment of advanced cancers. Oncologist. 2011;16(6):788-799.

32. Ma PC, Tretiakova MS, MacKinnon AC, et al. Expression and mutational analysis of MET in human solid cancers. Genes Chromosomes Cancer. 2008;47(12):1025-1037.

33. Rikova K, Guo A, Zeng Q, et al. Global survey of phosphotyrosine signaling identifies oncogenic kinases in lung cancer. Cell. 2007;131(6): $1190-1203$.

34. Ma PC, Jagadeeswaran R, Jagadeesh S, et al. Functional expression and mutations of c-Met and its therapeutic inhibition with SU11274 and small interfering RNA in non-small cell lung cancer. Cancer Res. 2005;65(4):1479-1488.

35. Ma PC, Maulik G, Christensen J, Salgia R. c-Met: structure, functions and potential for therapeutic inhibition. Cancer Metastasis Rev. 2003;22(4):309-325.

36. Beau-Faller M, Ruppert AM, Voegeli AC, et al. MET gene copy number in non-small cell lung cancer: molecular analysis in a targeted tyrosine kinase inhibitor naive cohort. J Thorac Oncol. 2008;3(4):331-339. 
37. Cappuzzo F, Janne PA, Skokan M, et al. MET increased gene copy number and primary resistance to gefitinib therapy in non-small-cell lung cancer patients. Ann Oncol. 2009;20(2):298-304.

38. Go H, Jeon YK, Park HJ, Sung SW, Seo JW, Chung DH. High MET gene copy number leads to shorter survival in patients with non-small cell lung cancer. J Thorac Oncol. 2010;5(3):305-313.

39. Kanteti R, Yala S, Ferguson MK, Salgia R. MET, HGF, EGFR, and PXN gene copy number in lung cancer using DNA extracts from FFPE archival samples and prognostic significance. J Environ Pathol Toxicol Oncol. 2009;28(2):89-98.

40. Onitsuka T, Uramoto H, Ono K, et al. Comprehensive molecular analyses of lung adenocarcinoma with regard to the epidermal growth factor receptor, K-ras, MET, and hepatocyte growth factor status. J Thorac Oncol. 2010;5(5):591-596.

41. Dziadziuszko R, Wynes MW, Singh S, et al. Correlation between MET gene copy number by silver in situ hybridization and protein expression by immunohistochemistry in non-small cell lung cancer. JThorac Oncol. 2012;7(2):340-347.

42. Ichimura E, Maeshima A, Nakajima T, Nakamura T. Expression of c-met/HGF receptor in human non-small cell lung carcinomas in vitro and in vivo and its prognostic significance. Jpn J Cancer Res. 1996;87(10):1063-1069

43. Tsao MS, Liu N, Chen JR, et al. Differential expresssion of Met/ hepatocyte growth factor receptor in subtypes of non-small cell lung cancers. Lung Cancer. 1998;20(1):1-16.

44. Tsuta K, Kozu Y, Mimae T, et al. c-MET/phospho-MET protein expression and MET gene copy number in non-small cell lung carcinomas. J Thorac Oncol. 2012;7(2):331-339.

45. Lutterbach B, Zeng Q, Davis LJ, et al. Lung cancer cell lines harboring MET gene amplification are dependent on Met for growth and survival. Cancer Res. 2007;67(5):2081-2088.

46. Goetsch L, Broussas M, Fabre-Lafay S et al. Abstract 2448: h224G11, a humanized whole antibody targeting the c-Met receptor, induces c-Met down-regulation and triggers ADCC functions. Cancer Research: 2010;70(8)(Suppl 1):2448.

47. Puri N, Khramtsov A, Ahmed S, et al. A selective small molecule inhibitor of c-Met, PHA665752, inhibits tumorigenicity and angiogenesis in mouse lung cancer xenografts. Cancer Res. 2007;67(8): 3529-3534.

48. Eathiraj S, Palma R, Volckova E, et al. Discovery of a novel mode of protein kinase inhibition characterized by the mechanism of inhibition of human mesenchymal-epithelial transition factor (c-Met) protein autophosphorylation by ARQ 197. J Biol Chem. 2011;286(23):20666-20676.

49. Munshi N, Jeay S, Li Y, et al. ARQ 197, a novel and selective inhibitor of the human c-Met receptor tyrosine kinase with antitumor activity. Mol Cancer Ther. 2010;9(6):1544-1553.

50. Underiner TL, Herbertz T, Miknyoczki SJ. Discovery of small molecule c-Met inhibitors: Evolution and profiles of clinical candidates. Anticancer Agents Med Chem. 2010;10(1):7-27.

51. Pan BS, Chan GK, Chenard M, et al. MK-2461, a novel multitargeted kinase inhibitor, preferentially inhibits the activated c-Met receptor. Cancer Res. 2010;70(4):1524-1533.

52. Gu X, Wang C, Yu Y, et al. Inhibition of HGF/C-MET pathway by ARQ 197: characterization of pharmacodynamic markers in vitro and in vivo. Poster presented at the 2009 American Association for Cancer Research Annual Meeting, April 18-22, 2009, Denver, CO, USA.

53. Anderson K, Li C, Moreau J, et al. ARQ 197, a small molecule inhibitor of c-MET prevents bone metastasis in a humanized mouse model of breast cancer. Poster B184 presented at the AACR-NCI -EORTC international conference, October 22-26, 2007, San Francisco, CA, USA.

54. Li Y, Chen D, Zhou W, et al. Broad spectrum anti cancer activity of ARQ 197, a highly selective oral c-MET inhibitor in multiple xenograft models. Poster 2216 presented at the 2007 American Association for Cancer Research Annual Meeting, April 14-18, 2007, Los Angeles, CA, USA.
55. Rosen L, Senzer N, Nemunaitis J, et al. Phase I dose escalation study and signs of anti-metastatic activity of ARQ 197, a selective c-Met inhibitor. Paper presented at the AACR-NCI-EORTC international conference, October 22-26, 2007, San Francisco, CA, USA.

56. Mekhail T, Rich T, Rosen L, et al. Final results: a dose escalation phase I study of ARQ 197, a selective c-Met inhibitor, in patients with metastatic solid tumors. J Clin Oncol. 2009;27(Suppl 15):3548.

57. Garcia A, Rosen L, Cunningham C, et al. Phase I study of ARQ 197, a selective inhibitor of the c-Met RTK in patients with metastatic solid tumors reaches recommended phase 2 dose. J Clin Oncol. 2007;25 Suppl 18:3525.

58. Yap TA, Frentzas S, Tunuriu N, et al. Final results of a pharmacokinetic (PK) and pharmacodynamic (PD) phase I trial of ARQ 197 incoporating dynamic contrast enhanced (DCE) magnetic resonance imaging (MRI) studies investiagting the antiangiogenic activity of selective c-Met inhibition. J Clin Oncol. 2009;27(15):3523.

59. Goldman J, Rosen L, Laux I, et al. Phase I dose escalation trial (ARQ 197-111) evaluating combination of selective c-Met inhibitor ARQ 197 and erlotinib. Oral presentation A6.5 at 13th International Association for the Study of Lung Cancer World Conference, July 31 to Aug 2009, San Francisco, CA, USA.

60. Laux GJ, Just R, Brady K, et al. Phase I dose escalation trial (ARQ 197-111) evaluating combination of selective c-MET inhibitor ARQ 197 and erlotinib. J Clin Oncol. 2009;27(15):3549.

61. Wagner A, Demetri GD, Choy E, et al. Preliminary results from a phase 2 study of ARQ 197 in patients with microphthalmia transcription factor family (MiT) associated tumors. Oral presentation 39313 to Connective Tissue Oncology Society, November 5-7, 2009, Miami, FL, USA.

62. Adjei AA, Sosman JA, Dy GK, et al. A phase I dose escalation trial of the c-MET inhibitor ARQ 197 administered in combination with sorafenib in adult patients with advanced solid tumors. Poster 3024 presented at American Society of Clinical Oncology scientific meeting, June 4-8, 2010, Chicago, IL, USA.

63. Camacho L, Chen CL, Kazakin J, et al. A phase 1b dose escalation trial evaluating ARQ 197 administered in combination with gemcitabine to patients with advanced solid tumors. Paper presented at American Society of Clinical Oncology scientific meeting, June 4-8, 2010, Chicago, IL, USA.

64. ClinicalTrials.gov. ARQ 197 in combination with chemotherapy in patients with metastatic colorectal cancer. 2010. Available from: http://clinicaltrials.gov/ct2/show/NCT01075048. Accessed April 17, 2014.

65. Goldman JW, Laux I, Chai F, et al. Phase 1 dose-escalation trial evaluating the combination of the selective MET (mesenchymal-epithelial transition factor) inhibitor tivantinib (ARQ 197) plus erlotinib. Cancer. 2012;118(23):5903-5911.

66. Sequist LV, von Pawel J, Garmey EG, et al. Randomized phase II study of erlotinib plus tivantinib versus erlotinib plus placebo in previously treated non-small-cell lung cancer. J Clin Oncol. 2011;29(24): 3307-3315.

67. Scagliotti GV, Novello S, Schiller JH, et al. Rationale and design of MARQUEE: a phase III, randomized, double-blind study of tivantinib plus erlotinib versus placebo plus erlotinib in previously treated patients with locally advanced or metastatic, nonsquamous, non-small-cell lung cancer. Clin Lung Cancer. 2012; 13(5):391-395.

68. [No authors listed]. Arqule and Daiichi Sankyo announce discontinuation of phase III MARQUEE clinical trial in non-small cell lung cancer. 2012. Available from: http://files.shareholder.com/downloads/ ARQL/0x0x603004/d4d3b6d2-4ce1-467f-979b-43f4c2613e01/. Accessed April 17, 2014.

69. INC-QA. EDGAR online via COMTEX-ITEM 2. Management discussion and analysis of financial condition and results of operations. May, 2013. Available from: http://www.marketwatch.com/story/10-q-arquleinc-2013-05-08. Accessed April 16, 2014 
70. European Society for Medical Oncology. ESMO@ECC 2013: a Phase III study of tivantinib plus erlotinib did not meet a primary endpoint in patients with locally-advanced or metastatic, nonsquamous NSCLC. 2013. Available from: http://www.esmo.org/ Oncology-News/A-Phase-III-Study-of-Tivantinib-Plus-Erlotinib-DidNot-Meet-a-Primary-Endpoint-in-Patients-with-Locally-advanced-orMetastatic-Non-squamous-NSCLC. Accessed April 17, 2014.

71. ClinicalTrials.gov. A Phase 3, randomized, double-blinded, placebocontrolled study of ARQ 197 plus erlotinib versus placebo plus erlotinib (ATTENTION). Available from: http://clinicaltrials.gov/ct2/show/ NCT01377376. Accessed April 17, 2014.

72. [No authors listed]. Kyowa Hakko Kirin announces temporary suspension of patient enrollment for Phase 3 clinical study of ARQ 197 (tivantinib) in combination with erlotinib in non-small-cell lung cancer patients. http://www.kyowa-kirin.com/news_releases/2012/pdf/ e20120830_01.pdf. Accessed April 17, 2014.

73. [No authors listed]. Kyowa Hakko Kirin announces discontinuation for phase 3 clinical study of ARQ 197 (Tivantinib) in combination with erlotinib in Non-small cell lung cancer patients. Available from: http:// www.kyowa-kirin.com/news_releases/2012/pdf/e20121030_01.pdf. Accessed April 17, 2014.
74. ClinicalTrials.gov. A Phase 2 randomized open-label study of erlotinib plus tivantinib (ARQ 197) versus single agent chemotherapy in previously treated KRAS mutation positive subjects with locally advanced or metastatic non-small cell lung cancer. Available from: http://clinicaltrials.gov/ct2/show/NCT01395758?term=nct01395758\& rank=1. Accessed April 17, 2014.

75. ClinicalTrials.gov. ARQ 197 plus erlotinib in patient with locally advanced or metastatic EGFR mutation-positive non-small-cell lung cancer. Available from: http://clinicaltrials.gov/ct2/show/NCT 01580735? term $=$ Tivantinib+and+lung+cancer\&rank $=6$. Accessed April 17, 2014.

76. Katayama R,Aoyama A,Yamori T, et al. Cytotoxic activity of tivantinib (ARQ 197) is not due solely to c-MET inhibition. Cancer Res. 2013;73(10):3087-3096.
Cancer Management and Research

\section{Publish your work in this journal}

Cancer Management and Research is an international, peer-reviewed open access journal focusing on cancer research and the optimal use of preventative and integrated treatment interventions to achieve improved outcomes, enhanced survival and quality of life for the cancer patient. The journal welcomes original research, clinical \& epidemiological

\section{Dovepress}

studies, reviews \& evaluations, guidelines, expert opinion \& commentary, case reports \& extended reports. The manuscript management system is completely online and includes a very quick and fair peerreview system, which is all easy to use. Visit http://www.dovepress.com/ testimonials.php to read real quotes from published authors. 